\title{
Performance enhancement of a diesel engine with a rotating injector: A numerical study
}

\author{
P. Chandrasekar and Natteri M. Sudharsan* \\ Department of Mechanical Engineering, Rajalakshmi Engineering College, Chennai, India \\ * Corresponding Author: sudharsann@asme.org
}

$\begin{array}{ll}\text { Submitted } & : 21 / 01 / 2020 \\ \text { Revised } & : 02 / 02 / 2021 \\ \text { Accepted } & : 12 / 02 / 2021\end{array}$

\begin{abstract}
Improving engine performance is a constant challenge, and various methodologies have been adopted by researchers around the world. In this work, the dispersion characteristics of a rotating injector are studied by varying the umbrella angle (UA) followed by its combustion characteristics and comparing it to a static 3-hole injector. The present numerical study is benchmarked with the experimental data obtained from open literature for a 2-hole injector with various umbrella angles. The volume fraction of the dispersed fuel along with its spray structure in relation to spray width is compared. This is done by processing the numerical contour plot using LabView image processing utility with appropriate calibration. From this study, the $130^{-}$degree UA injector configuration was found to be effective when compared with the 70. The combustion characteristics are now studied for this injector. It is found that the rotating injector has better dispersion and lowers $\mathrm{NO}_{\mathrm{x}}$ by $14 \%$ when compared to a static injector with a very marginal loss in thermal efficiency. The rotary system has a lower heat release but a wider spread in comparison to a static case. This helps in marginally reducing the in-cylinder temperature and pressure lower $\mathrm{NO}_{\mathrm{x}}$.
\end{abstract}

Keywords: Diesel fuel injection; Rotating injector; Umbrella angle; Volume fraction; CFD.

\section{NOMENCLATURE}

$\begin{array}{ll}\text { aTDC } & - \text { after Top Dead Centre } \\ \text { bTDC } & - \text { before Top Dead Centre } \\ \text { CC } & - \text { Cubic capacity } \\ \text { ECFM-3Z } & - \text { Extended Coherent Flame Model-3 Zone } \\ \text { HRR } & - \text { Heat Release Rate } \\ \text { UA } & - \text { Umbrella angle } \\ \text { VOF } & - \text { Volume of Fraction } \\ \text { RD } & - \text { Reitz Diwakar } \\ \text { RGB } & - \text { Red Green Blue } \\ \text { SW } & - \text { Spray Width } \\ \text { Tke } & - \text { Turbulent kinetic energy. }\end{array}$




\section{INTRODUCTION}

Power hungry equipment and machines require high capacity engines. These engines must be able to work efficiently under harsh environments. A critical requirement for high capacity equipment is that it must achieve extremely high performance by limiting the size and weight of the power plant. Hence, it would be welcome to have a compact power plant that delivers better performance, while at the same time withstanding harsh environments (ambient) and operational abuse (road or off-road conditions). Emission control will also be of interest for such engines. Good dispersion and atomization help in complete combustion with improved thermal efficiency. The sheer sizes of these engines require injectors of high pressure and throw to ensure that the fuel air charge can be efficiently combusted. A method of approach is desirable, wherein efficiency of high capacity engines can be improved with lower pressure injection. This would reduce the demand on the fuel pump and thereby the cost. Further research is performed to choose an appropriate methodology in this direction.

Literature survey was done to suggest a method of achieving higher efficiency for high capacity engines. Latest diesel injection uses high injection pressure and small holes to improve the fuel atomization, evaporation, and mixture homogeneity (Su TF et al., 1995, Naber JD and Siebers, 1996, Siebers D and Higgins B, 2001, Bergstrand P et al., 2002, Nishida K et al., 2008) and to reduce engine emissions (Kobori S et al., 1996, Montgomery DT et al., 1996, Bergstrand P and Denbrantt I, 2001, Iida N et al., 2001). The engine combustion and emission are strongly correlated and crucial to the atomization and vaporization process of the injected fuel (Dec JE 1997). However, the spray characteristics are strongly influenced by the flow dynamics inside the injector nozzle, which largely depend on the nozzle geometry because of cavitation and turbulence (C Soteriou et al., 2001).

An experimental study on the effect of orifice configuration to the injection rate under maximum needle lift in a common-rail fuel injection system was studied (J Benajes et al., 2004). The authors observed that, compared to a cylindrical orifice, a conical orifice had a reduced cavitation and injection rate with increased flow efficiency and higher exit velocity. Choking conditions are observed with cylindrical nozzles, whereas, for conical nozzles, the mass flow rate was always proportional to the square root of pressure drop, indicating the absence of cavitation at the nozzle exit (Payri et al., 2005). For a cylindrical nozzle, they also observed an increase in injection velocity due to the presence of vapor at orifice exit. Han et al. (2002) compared conical and cylindrical nozzles and found that the nozzle geometry influences the primary breakup region.

The effect of orifice geometry on spray penetration, liquid length, and cone angle has also been examined. Blessing et al. (2003) and Payri et al. (2004) reported that, for nonevaporating sprays, the increase in conicity results in greater liquid penetration and smaller cone angle. Xusheng Zhang et al. (2016) analyzed the near-nozzle breakup by varying the umbrella angle (UA) in a two-hole injector under transient needle lift. They felt that this study is vital to understand the link between the ejected fuel and its atomization. Magnus Sjoberg (2001) observed that spray propagation was found to be influenced by the effect of nozzle rotation than air swirl. The aim of the fuel injection process is to mix air and fuel at a faster rate within the available time. Creating swirl motion inside the engine cylinder will improve the air fuel mixing at a faster rate. Swirl motion can be generated by either by varying piston bowl geometry or a rotating injector. In this present work, a rotating injector has been numerically studied using computational fluid dynamics for dispersion and combustion characteristics.

The review indicates that the impact of nozzle orifice geometry on the injector flow and spray pattern has been reviewed to some extent, but its influence on engine combustion and emission is not that well established. The influence of nozzle geometry on spray and combustion characteristics has been studied both theoretically and experimentally. But to the best of our knowledge, the influence of a rotating injector has not been studied. Based on the review, the current work focuses on a numerical study on the spray characteristics such as spray width and vapor fraction. This qualitative and quantitative study is performed for static and rotating injector under cold flow and combustion conditions. 
In order to study the effect of rotating injector, the following is the method of approach:

1. Numerical simulation of a two-hole injector for dispersion and spray width, compared with experimental results (Xusheng Zhang et al., 2016).

2. Numerical results also present the Volume of Fraction (VOF) of the fuel and hence a better understanding of the dispersed fuel compared to flow visualization obtained experimentally.

3. The rotating frame is now incorporated and compared with a static injector.

4. Combustion simulation of static injector with a piston movement for an engine speed of $1500 \mathrm{rpm}$ is compared with the same rotating injector at $1500 \mathrm{rpm}$.

Thus, the current numerical study presents additional information on the volume fraction of the fuel and its importance from the perspective of combustion, which has hitherto not been published to the author's best of knowledge.

\section{NUMERICAL MODEL}

\subsection{Injector}

From Xusheng Zhang et al. (2016), two cases having umbrella angle of 70 and 130 degrees designated as UA 70 degree and UA 130 degree with orifices $0.12 \mathrm{~mm}$ and sac diameter of $0.7 \mathrm{~mm}$ are considered. Sac is the small volume between the valve seat and orifice, and it is labeled in Figure 7.

\subsection{Numerical Methodology}

The numerical scheme involves the transient linear movement for the needle and a moving reference frame for the rotating injector. The fuel studied is diesel $\left(\mathrm{C}_{12} \mathrm{H}_{23}\right)$ inside a chamber filled with Nitrogen at 1 bar as was done experimentally (Xusheng Zhang et al., 2016). The spray is quantified for width and vapor fraction. The vapor fraction is the amount of fuel at the interface for the fuel and Nitrogen. The width is measured by making use of LabView software and explained in detail later. The vapor fraction at the interface is obtained from the CFD software Star CCM+ Version 12.02.011 (Star CCM+2017).

The VOF scheme was utilized in this numerical study. This VOF-VOF scheme handles multiphase interaction of a primary fluid with a secondary fluid. Here, the diesel liquid and vapor is considered as primary multiphase, and the corresponding secondary phase is Nitrogen. The Reynolds averaged Navier-Stokes equation was solved using the k- $\varepsilon$ model for turbulence. For combustion simulation, the fuel break-up and atomization were modelled using Reitz Diwakar approach provided in the Star-CD CFD software.

\subsection{Computational Domain}

The effect of nozzle geometry on the injector flow was examined by considering the injector having two holes with UA 70 and UA 130 degrees. To simulate this, a constant volume combustion chamber was used with the dimension of $116 \mathrm{~mm}$ stroke length and $96 \mathrm{~mm}$ diameter. The effect of spray width was examined. A trimmed cell mesh was used with volumetric control in the injector and combustion chamber. Five-layer prism cells totaling 3.3 $\mu \mathrm{m}$ were used to resolve the boundary layer. The first grid point from the wall is of $0.25 \mu \mathrm{m}$ in size with an increasing growth size of 1.3. In order to check if this grid point is within the boundary layer, the wall $\mathrm{y}+$ is checked and found to be 96 . It is desirable that $\mathrm{y}+$ is in the range from 50 to 300 . Thus, $\mathrm{y}+=96$ clearly ensured that the flow inside $\log$ layer is adequately captured. 


\subsection{Field Function Equations}

Field functions allow users to customize the solver for altering the boundary conditions and such other parameters during the course of the solution. Here, the boundary conditions are altered due to the lifting of the needle. The needle lift in terms of distance vs time is provided as a table, and a field function is used to access and interpolate the data. This field function is presented in equation (1). It is to be noted that in actual experiments the needle starts from a fully closed condition. Numerically, this will be analogous to a no flow condition. Hence, in this simulation, the needle lift was slightly left open at $110 \mu \mathrm{m}$ during start and end of the lift cycle.

[0, interpolate Table(@Table("Disp130"), "time", LINEAR, "lift", \$\{Time\}), 0]

\subsection{Boundary Conditions}

As injection pressure alone was provided in the experimental study, it was necessary to estimate the mass flow at that injection pressure. A preliminary study was done to estimate the mass flow rate and it was found to be 0.01 $\mathrm{kg} / \mathrm{s}$ at 300 bars. The boundary conditions are summarized in Table 1. The k- $\varepsilon$ turbulence model was chosen as it was found to be more closure to experimental results in simulating combustion process (Yu et al., 2017).

Using the above set of boundary conditions, the solution was obtained until convergence. A mesh independent study was also done to ensure numerical stability. The simulation was performed for 5 and 10 million cells, and spray width was benchmarked with the experimental results (Xusheng Zhang et al., 2016). The scheme for spray width and volume fraction measurement is presented in the next section.

\subsection{Image processing}

To measure the spray width, LabVIEW software has been used for processing the image for further analysis. The CFD software was postprocessed to visualize the volume fraction of the fuel. This was exported as an image file. The original RGB (Red, Green, Blue) image is converted into grey scale. All images were imported with the same pixel density (1592 X 660). In order to measure the spray width, the edge needs to be captured, and the pixel to pixel length is to be calculated. The image was calibrated using a known value of nozzle diameter $120 \mu \mathrm{m}$ and found to be equal to 99 pixels. The process is given as a flow chart in Figure 1. The spray width of the diesel was measured as the distance between right cone and left cone perpendicular to the spray axis at the location of $1.5 \mathrm{~mm}$ away from the nozzle exit and presented in Xusheng Zhang et al. (2016). The same location is also used in this present study for validation.

Table 1. Summary of Boundary Conditions and Numerical values.

\begin{tabular}{|l|l|}
\hline \multicolumn{1}{|c|}{ Description } & \multicolumn{1}{c|}{ Boundary conditions } \\
\hline Computational Geometry & \\
Orifice diameter $(\mathrm{mm})$ & 0.12 \\
Sac diameter $(\mathrm{mm})$ & 0.7 \\
\hline
\end{tabular}




\begin{tabular}{|l|l|}
\hline Boundary Conditions & \\
Inlet & Mass flow $0.01 \mathrm{~kg} / \mathrm{s}$ \\
$\begin{array}{l}\text { Outlet } \\
\text { Wall }\end{array}$ & Pressure outlet \\
Needle Lift Ramp & Field Function $110-550-110 \mu \mathrm{m}(0-4.5 \mathrm{~ms})$ \\
\hline $\begin{array}{l}\text { Mesh Parameters } \\
\text { Base Size }\end{array}$ & Cylinder $-2.0 \mathrm{~mm}$ \\
& Needle $-0.01 \mathrm{~mm}$ \\
Prism layers & 5 with first layer $0.25 \mu m$ and growth rate 1.3 \\
\hline $\begin{array}{l}\text { Solver Settings } \\
\text { Volume fraction } \\
\text { Convective } \\
\text { Interpolation }\end{array}$ & 2nd order upwind \\
Eulerian multiphase & \\
Turbulence & Volume-Weighted mixture method \\
Multiphase interaction & k- $\varepsilon$ model \\
Volume of Fluid (VOF) & VOF-VOF phase interaction \\
\hline
\end{tabular}

\subsection{In-Cylinder Combustion}

Having simulated the two-hole injector for both static and Rotating frame, it was necessary to study the combustion efficiency and emission of the rotating injector in comparison with a static injector. For the purpose of comparison, an $839 \mathrm{cc}$ diesel engine is considered. This engine has a standard static three-hole injector consuming 40 milligrams per cycle. The engine specifications are presented in Table 2.

Table 2. Engine specification and condition.

\begin{tabular}{|c|c|}
\hline Description & Specification \\
\hline Cylinder bore $\times$ stroke $(\mathrm{mm})$ & $96 \times 116$ \\
\hline Compression ratio & 17.5: 1 \\
\hline Cubic capacity (cc) & 839 \\
\hline Connecting rod length $(\mathrm{mm})$ & 245 \\
\hline Combustion chamber geometry & Hemispherical piston bowl type \\
\hline Engine speed (rpm) & 1500 \\
\hline Injection system & Point injection \\
\hline Injection method & Static and Rotating \\
\hline Fuel used & $\mathrm{C}_{12} \mathrm{H}_{23}($ Jet $-\mathrm{A})$ \\
\hline
\end{tabular}




\begin{tabular}{|c|c|}
\hline Static injector & 3 holes \\
\hline Rotating injector & 3 holes \\
\hline Nozzle hole diameter $(\mathrm{mm})$ & 0.1 \\
\hline Mass of fuel injected $(\mathrm{mg})$ & 40 \\
\hline
\end{tabular}

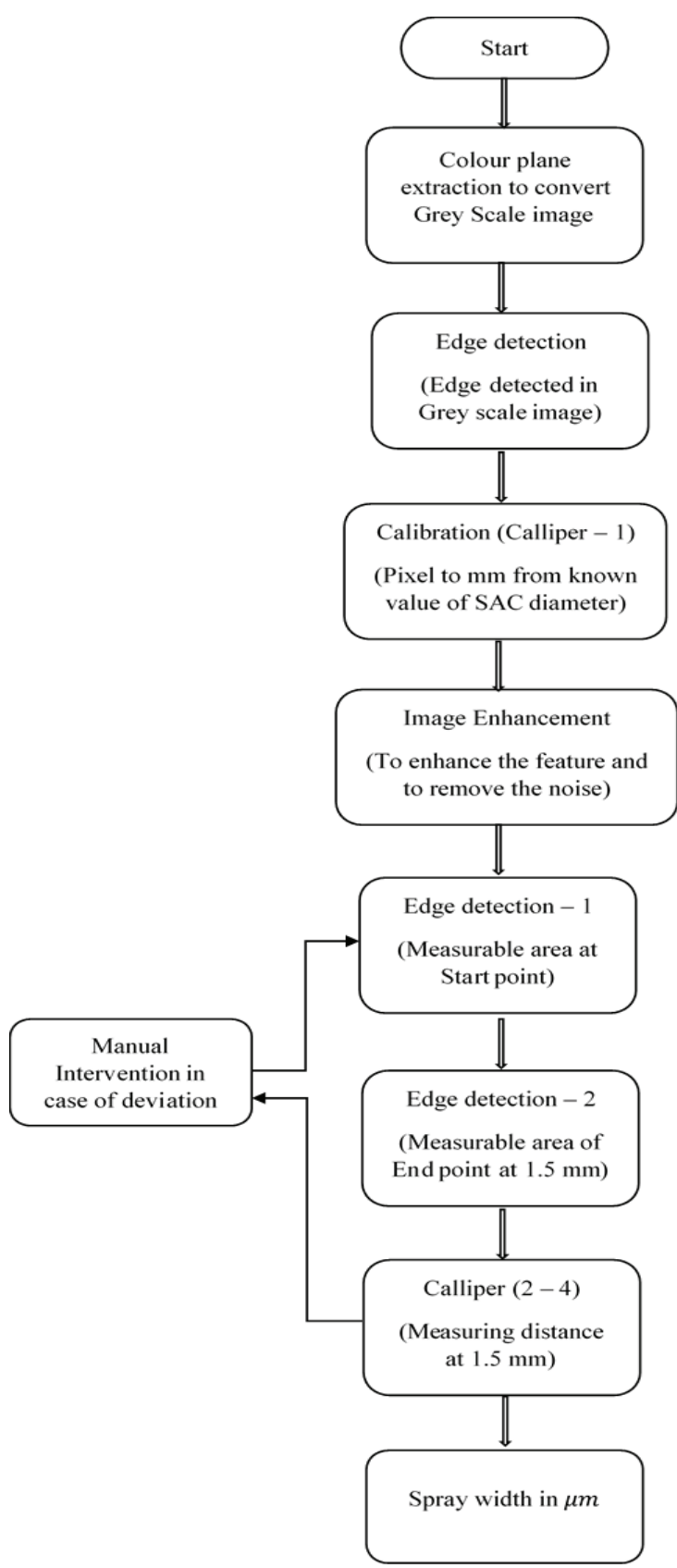

Figure 1. Flow Chart for spray width measurement using LabVIEW. 


\subsubsection{Moving mesh (Piston)}

The piston motion from BDC to TDC was simulated by creating an "event" file, which acts as an input to the Star-CD module. This "event" file is created with the help of es-ICE model. As the piston moves up or down, the mesh is automatically deactivated or activated. This is in conjunction with the time step used for the transient simulation. In order to capture the physics of combustion, the time step is reduced from coarse to fine. Initially, the time step is equal to 1 degree of crank rotation and reduced to 0.01 degree progressively. The time stepping sequence is tabulated in Table 3 from $180 \mathrm{bTDC}$ to 180 aTDC in both crank angle and physical time.
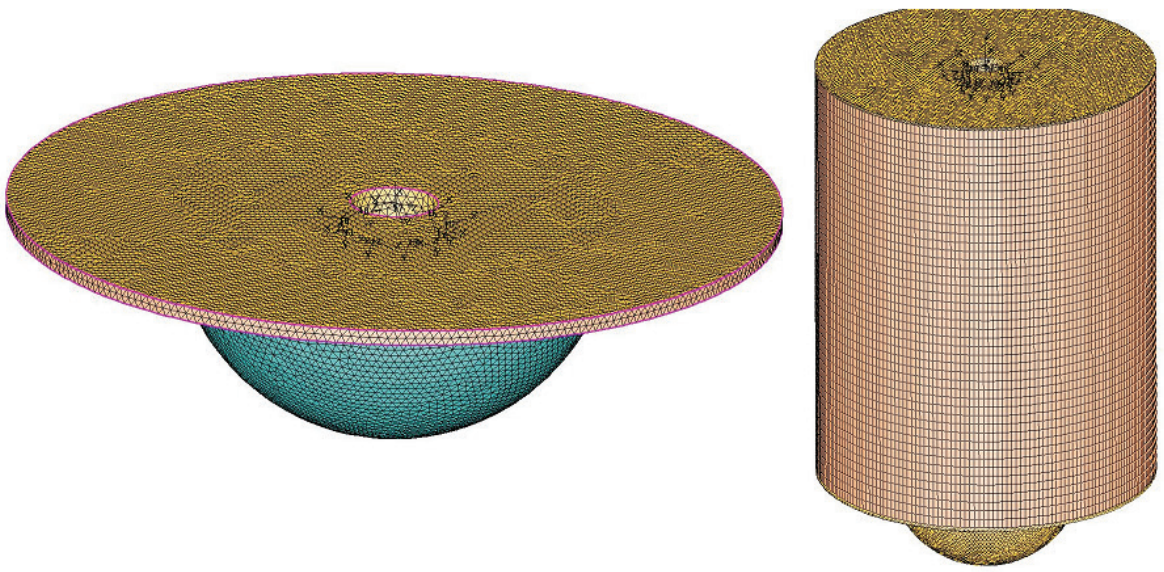

Figure 2. Piston position at TDC and BDC.

The methodology adopted for moving piston is the same for both static as well as rotating injector. This is now compared with a rotating injector having three holes and rotating at $1500 \mathrm{rpm}$ with the same consumption. Figure 2 presents the piston location at the two extreme locations.

Table 3. Crank Angle vs Time step.

\begin{tabular}{|c|c|c|c|}
\hline \multirow{2}{*}{ Sl. No } & \multirow{2}{*}{$\begin{array}{c}\text { Crank angle } \\
\text { (degree) }\end{array}$} & \multicolumn{2}{|c|}{ Time step } \\
\cline { 3 - 4 } & -180 to -140 & 1 & $\boldsymbol{\mu}$ \\
\hline 1 & -140 to -23 & 0.1 & 111.1 \\
\hline 2 & -23 to 5 & 0.01 & 11.11 \\
\hline 3 & 5 to 55 & 0.025 & 2.777 \\
\hline 4 & 55 to 80 & 0.1 & 11.11 \\
\hline 5 & 80 to 180 & 1 & 111.1 \\
\hline 6 & & \multicolumn{2}{|c}{} \\
\hline
\end{tabular}

\subsubsection{Modelling Rotating Injection}

A moving reference frame (MRF) is used for modelling the rotation. The injector is encapsulated in a separate domain within the cylinder. This domain will be set to a moving coordinate system. The interface between this rotating wall and the stationary wall (mesh) inside the cylinder will transfer information by interpolation. More details 
of MRF are available in user guide of STAR CCM+. The injection coordinates are so located to match the time step as mentioned in the Table 3. It is to be noted that the injection duration starts from 23 degrees bTDC to end of TDC totaling $4.5 \mathrm{~ms}$. During this injection timing, the rotating injector would have swept by 40.5 degrees. Thus, each injector 120 degrees apart will have injection coordinates from its location to maximum of 40.5 degrees. The physical time step during the injection duration as per serial number 3 is shown in Table 3, which is $1.111 \mu \mathrm{s}$, and for every time step, the injection coordinate would have rotated by a small angle. This procedure would mimic the physical rotation of the injector. The numerical results of a standard test case were first validated before modelling the present configuration.

\subsubsection{Fuel Spray and Combustion Modelling}

The fuel is to be modelled for atomization and dispersion. The fuel atomizes due to the combination of aerodynamics, cavitation and turbulence (Stiesch G, 2003). Among the atomization models available in the Star-CD (Star-CD, 2016), the Reitz Diwakar (RD) model was prepared (X. Margot et al., 2008). The RD break-up model is used in conjunction with the RD atomization model. The choice is based on studies presented in open literature (X. Margot et al., 2008, S. Hossainpour and A.R. Binesh, 2009 and Hajime Fujimoto et al., 2009). The simulation process needs to capture fuel-air mixing, ignition, flame propagation, and species after combustion. After a detailed study, the ECFM - 3Z model was used (Star-CD, 2016).

\section{RESULTS AND DISCUSSION}

\subsection{Effect of UA on the Spray Width}

\subsubsection{Qualitative Analysis}

The spray characteristics due to needle opening and closing are presented qualitatively in Figure $3(\mathrm{a}-\mathrm{d})$ and Figure $4(\mathrm{a}-\mathrm{d})$ for the UA 70 degree and UA 130 degree cases, respectively. From Figures 3 and 4, the spray width is seen to be higher for both initial \& final stages (a) and (b), i.e., during needle lift and close in comparison to the steady stage as seen in (c) and (d). These images will be further processed for quantification of fuel fraction that qualitatively compares well with the experimental observations of (Lee JW et al., 2006, Habchi C et al., 2008). In the experimental study presented in Xusheng Zhang et al. (2016), it was observed that vortex flow was induced in the two-hole injector with an UA 70 degree through UA 160 degree. The spray width (SW) varied with UA, and the same is also observed numerically.

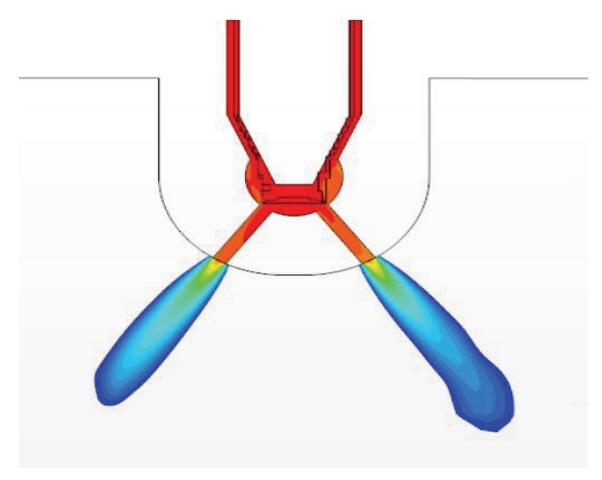

(a). Needle lift at $1.6 \mathrm{~ms}$ (Initial stage)

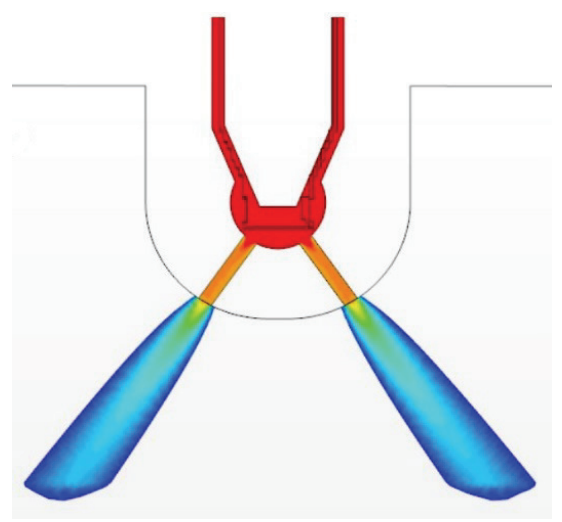

(b). Needle lift at $5.2 \mathrm{~ms}$ (Final stage) 


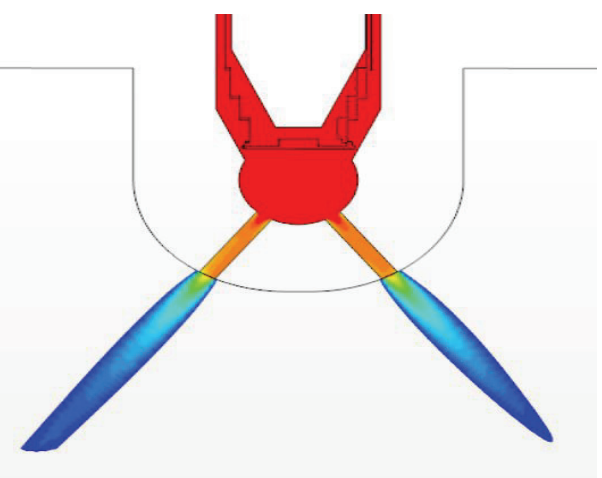

(c). Needle lift at $2.6 \mathrm{~ms}$ (Steady stage)

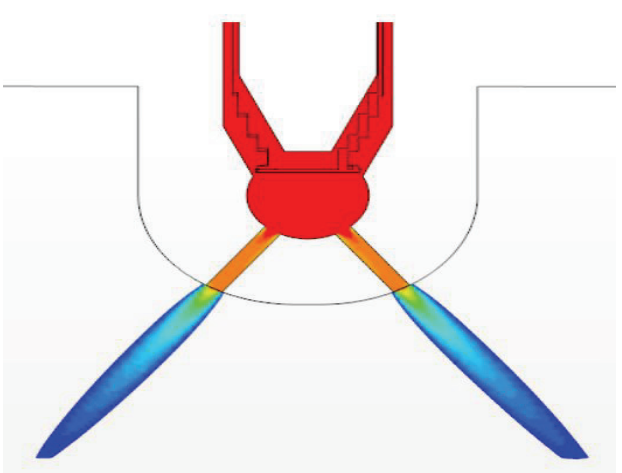

(d). Needle lift at $4.2 \mathrm{~ms}$ (Steady stage)

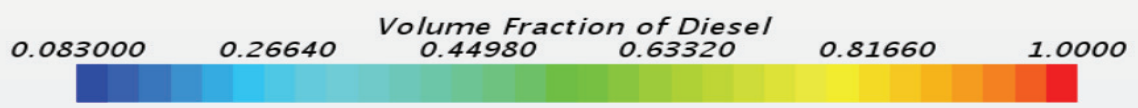

Figure 3. Detailed view of UA 70 degree with different needle position.

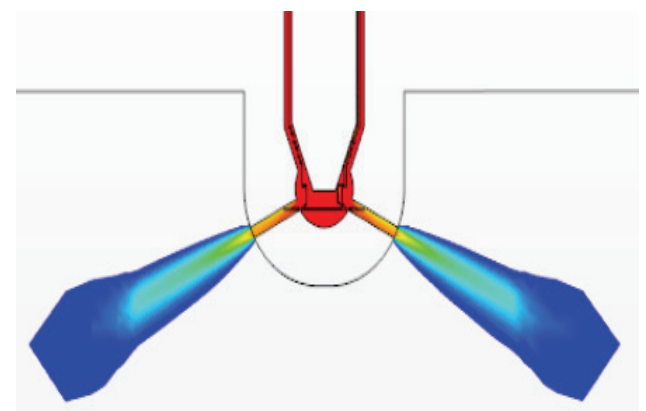

(a). Needle lift at $2.9 \mathrm{~ms}$ (Initial stage)

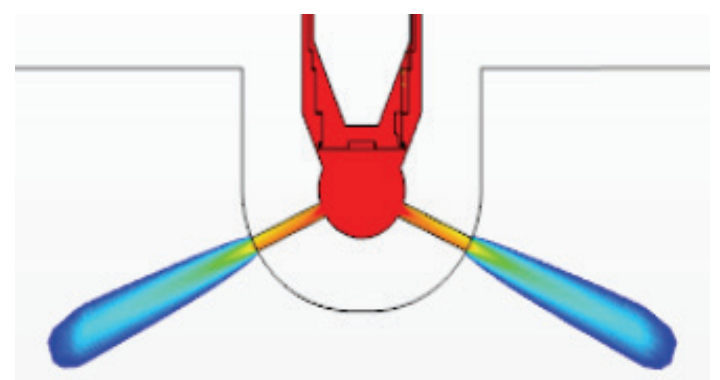

(c). Needle lift at $3.7 \mathrm{~ms}$ (Steady stage)

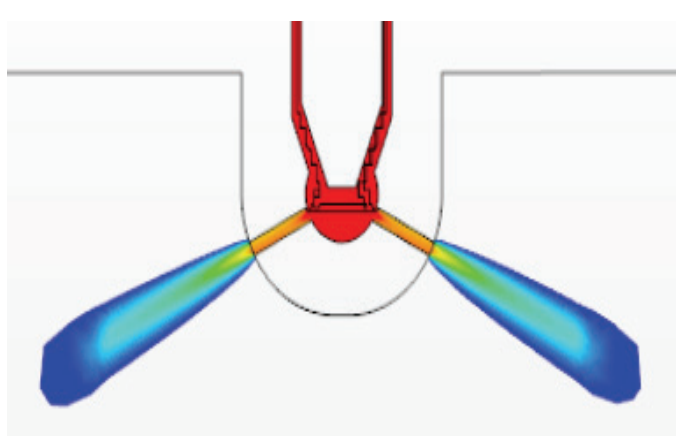

(b). Needle lift at $6 \mathrm{~ms}$ (Final stage)

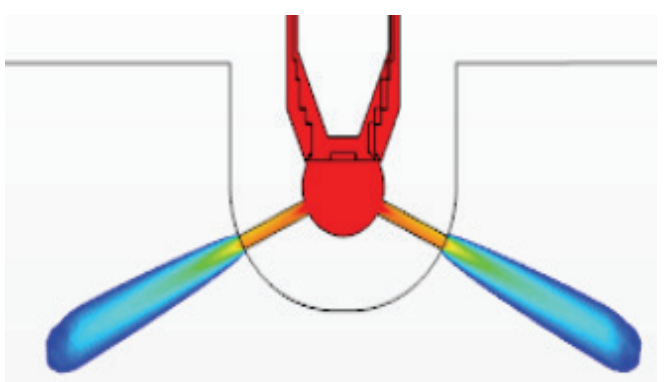

(d). Needle lift at $5.2 \mathrm{~ms}$ (Steady stage) 


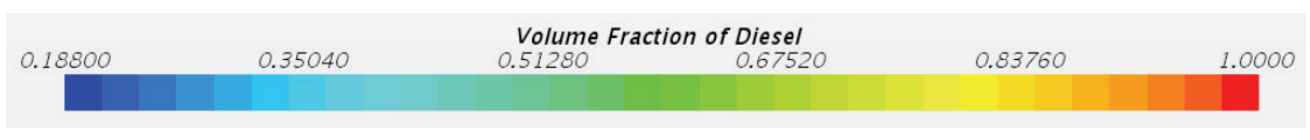

Figure 4. Detailed view of UA 130 degree with different needle position.

\subsubsection{Quantitative Analysis}

The effect of SW along with the volume fraction of fuel should throw additional information on the dispersion, which in effect leads to better combustion. It is to be noted that as the width increases, the fuel volume fraction will reduce with the increasing incidence of secondary phase (Nitrogen here). The vapor fraction was extracted from the CFD software and plotted as a band above and below the spray width obtained from the experimental results available in open literature (Figure 5). Spray width SW 78 and SW 83 represents percentage of liquid fraction in the fuel spray.

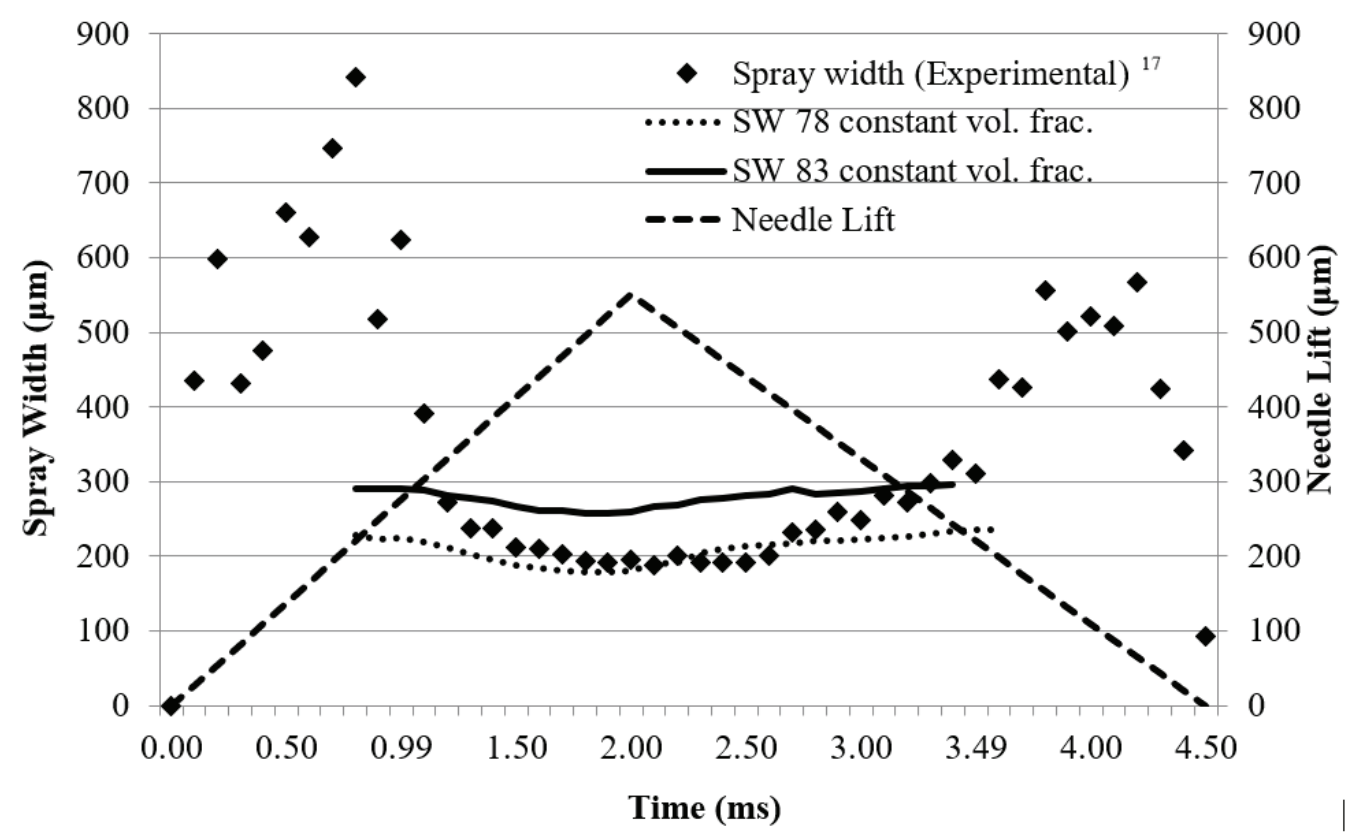

Figure 5. UA 130-degree optimum band width.

\subsubsection{Effect of Volume Fraction}

The volume fraction during the entire process of needle lifting to closure is extracted and same is presented in Figure 6. The volume fraction of diesel is more predominant in UA 130 degree when compared to UA 70 degree. The mean and standard deviation of UA 70 degree are $\mu=79.52 ; \sigma=7.37$ and for UA 130 degree $\mu=88.82 ; \sigma=$ 8.34. The mean $\mu=79.52$ means that $79.52 \%$ is fuel. Thus, it can be concluded that the fuel content in the UA 130 degree case is higher as opposed to UA 70-degree case with a higher standard deviation. Further investigations were done for steady state region, wherein the spray width distribution is almost stable, i.e., between the spray time of 0.79 
ms to $3.60 \mathrm{~ms}$ for UA 70 degree and $1.31 \mathrm{~ms}$ to $3.40 \mathrm{~ms}$ for UA 130 degree. It was found that the mean and standard deviation of UA 70 degree and UA 130 degree are $\mu=75.28 ; \sigma=2.86$ and $\mu=80.5 ; \sigma=2.53$, respectively.

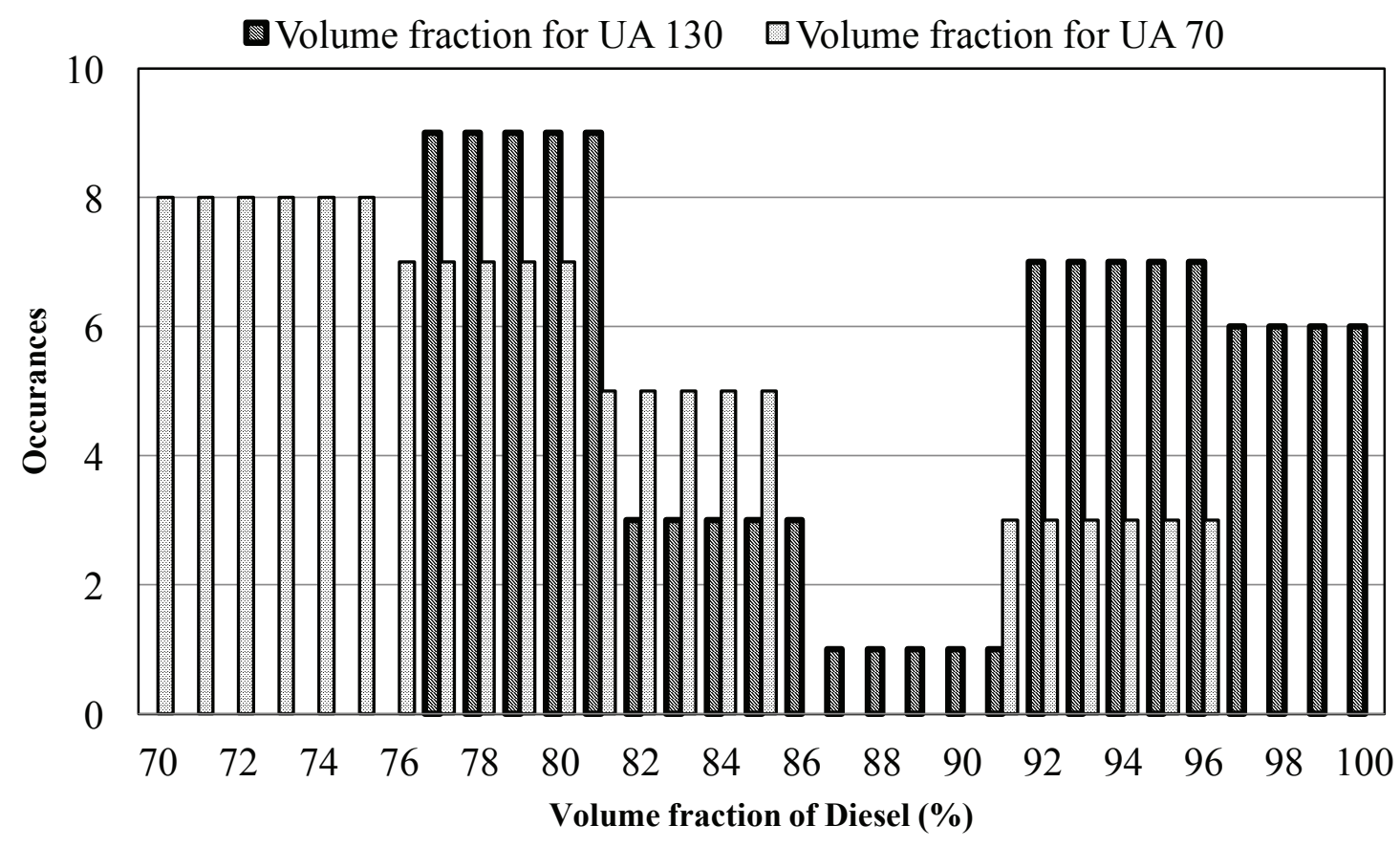

Figure 6. Comparison of volume of fraction of diesel spray (\%).

Table 4. t-Test. Two-Sample Assuming Unequal Variances (Overall Region).

\begin{tabular}{|l|c|c|}
\hline & UA130 & UA70 \\
\hline Mean & 88.82961538 & 79.52304348 \\
\hline Variance & 69.63704385 & 54.32557668 \\
\hline Observations & 26 & 23 \\
\hline Hypothesized Mean Difference & 0 & \\
\hline df & 47 & \\
\hline $\mathrm{t}$ Stat & 4.145341133 & \\
\hline $\mathrm{P}(\mathrm{T}<=\mathrm{t})$ one-tail & $7.02859 \mathrm{E}-05$ & \\
\hline $\mathrm{t}$ Critical one-tail & 1.677926722 & \\
\hline $\mathrm{P}(\mathrm{T}<=\mathrm{t})$ two-tail & 0.000140572 & \\
\hline $\mathrm{t}$ Critical two-tail & 2.01174048 & \\
\hline Standard deviation & 8.344881296 & 7.370588625 \\
\hline
\end{tabular}


Table 5. t-Test. Two-Sample Assuming Unequal Variances (Steady Region).

\begin{tabular}{|l|c|c|}
\hline & UA130 & UA70 \\
\hline Mean & 80.5 & 75.28571429 \\
\hline Variance & 6.425454545 & 8.167472527 \\
\hline Observations & 12 & 14 \\
\hline Hypothesized Mean Difference & 0 & \\
\hline df & 4.92957838 & \\
\hline t Stat & $2.48476 \mathrm{E}-05$ & \\
\hline $\mathrm{P}(\mathrm{T}<=\mathrm{t})$ one-tail & 1.710882067 & \\
\hline $\mathrm{t}$ Critical one-tail & $4.96952 \mathrm{E}-05$ & \\
\hline $\mathrm{P}(\mathrm{T}<=\mathrm{t})$ two-tail & 2.063898547 & \\
\hline $\mathrm{t}$ Critical two-tail & 2.534848032 & 2.857879026 \\
\hline Standard deviation & & \\
\hline
\end{tabular}

A student two-tailed t-test with $95 \%$ confidence level was performed for the dataset, and it was found that $t_{\text {stat }}>c_{\text {ritical }}$ which means that the fuel content available in the SW for UA 130 degree is higher than UA 70 degree in this stable region, and at the same time, the width is also larger in the UA 130 degree case. Thus, it can be concluded that UA 130 degree would perform better under combustion. The t-test two-sample unequal variances for overall and steady region are included in Table 4 and Table 5, respectively.

\subsubsection{Effect of Flow Rotation}

The fuel that is injected, reaching the sac and then to the nozzle exit. The UA angle variation causes a change in the sac volume and thereby alters the flow path of the fuel. The higher the sac volume space, the higher the chance of vortex formation and flow rotation. Figure 7 presents the velocity vector for the two UA cases studied here. The UA 130 has a larger sac space causing a stronger swirl flow. This may have an impact on the cavitation effects and the formation of vapor cone during ejection. This vapor was also observed in the experimental study (Xusheng Zhang et al., 2016). It was expected that such strong swirl force should help increase the vapor content and seen in the numerical simulation. This swirl effect inside the sac probably has an effect in increasing the spray width along with higher volume fraction of the fuel. 


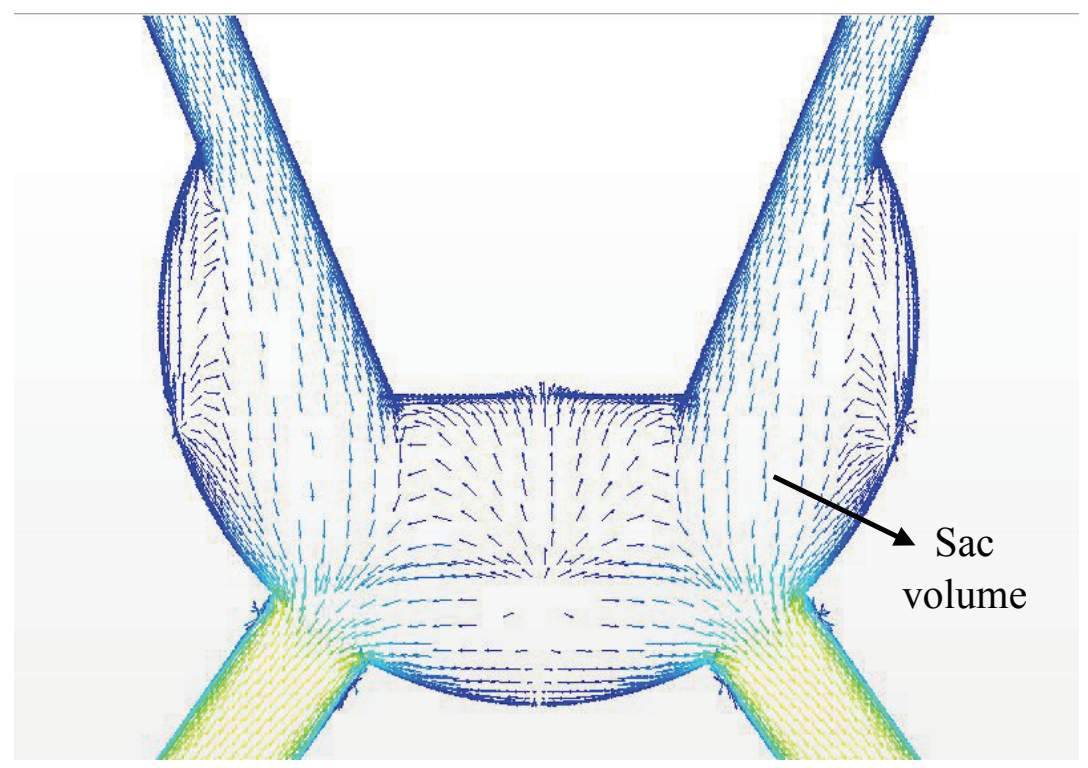

UA 70

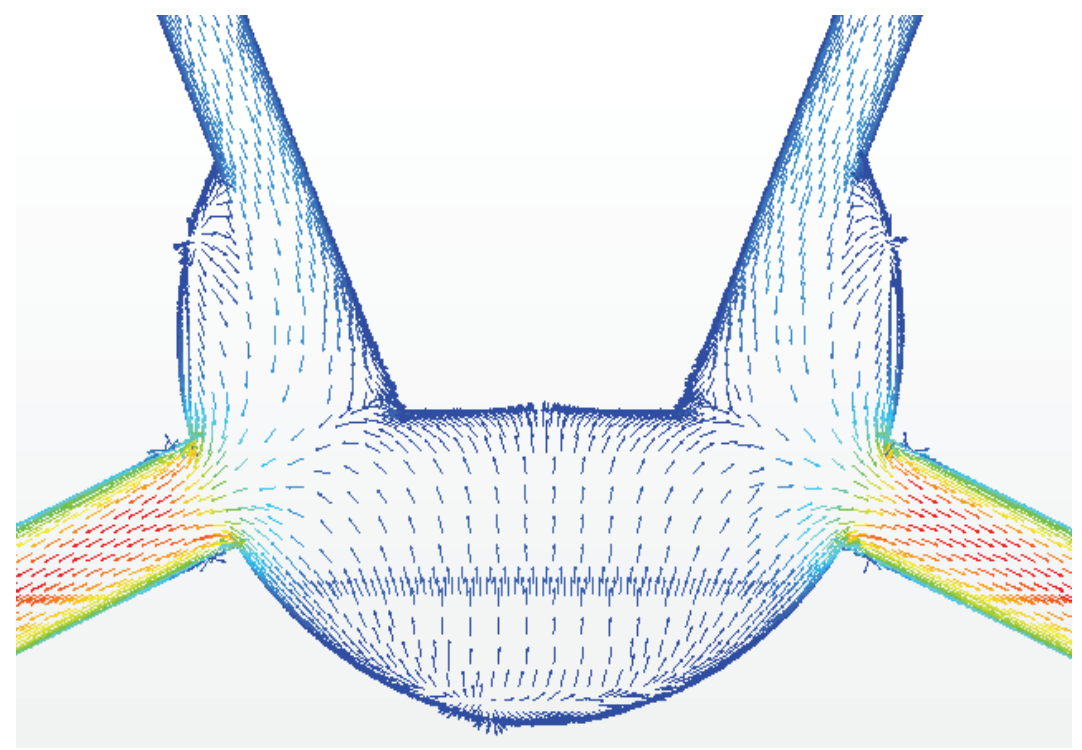

UA $130^{\circ}$

Figure 7. Vector distribution of fuel in injector bowl. 


\subsubsection{Effect of Injector Rotation}

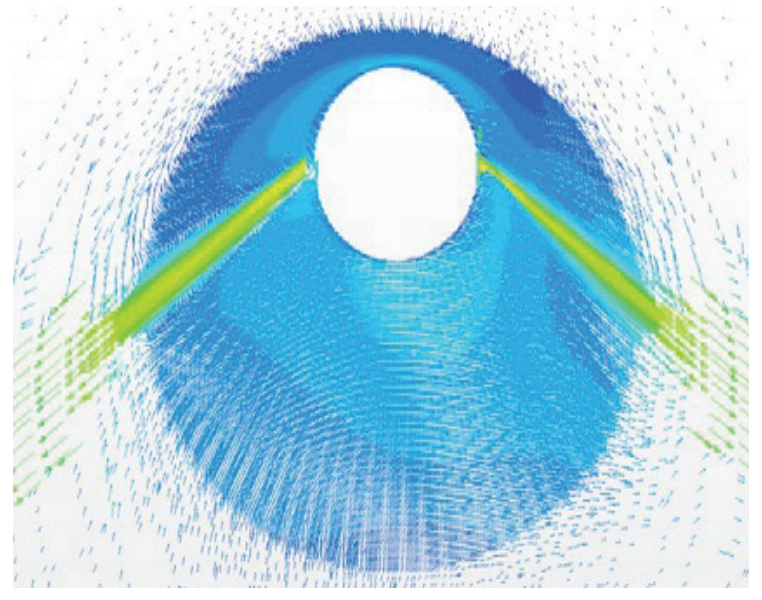

(a). UA $70^{\circ}$ Static in stable region

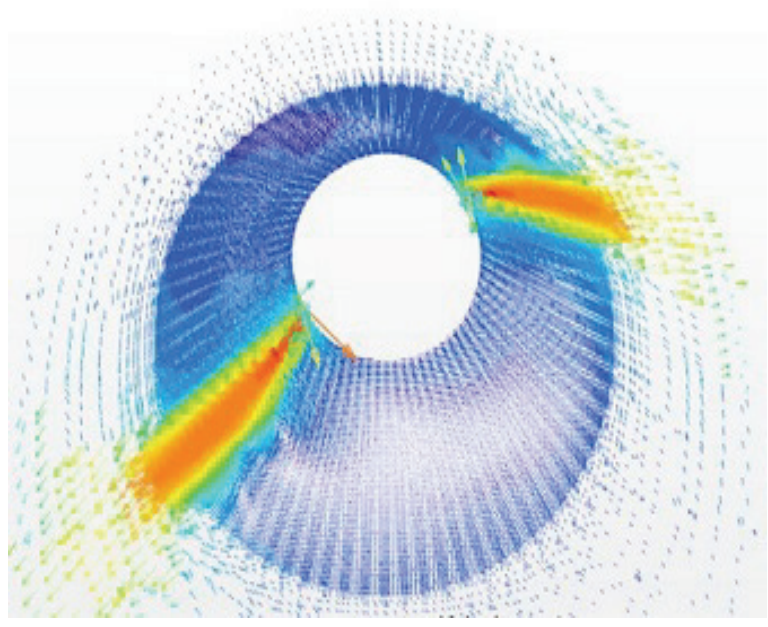

c). UA $70^{\circ}$ Rotation in stable region

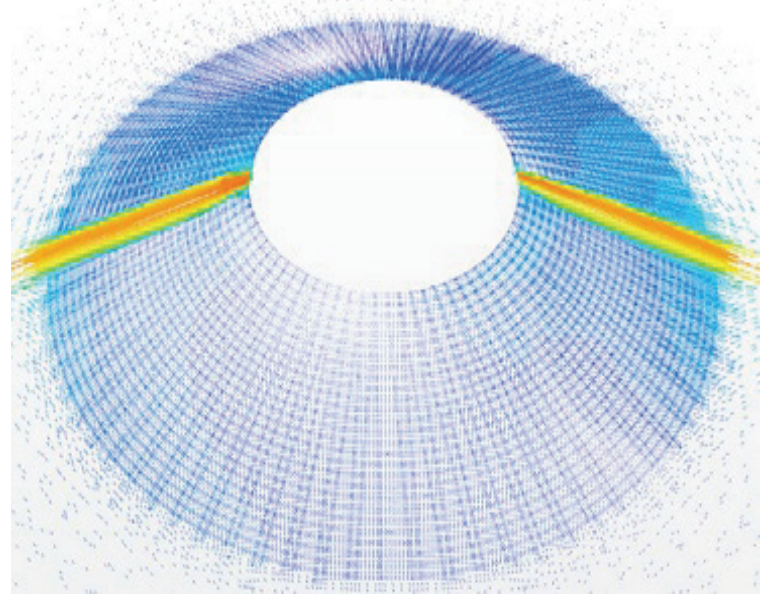

(b). UA $130^{\circ}$ Static in stable region

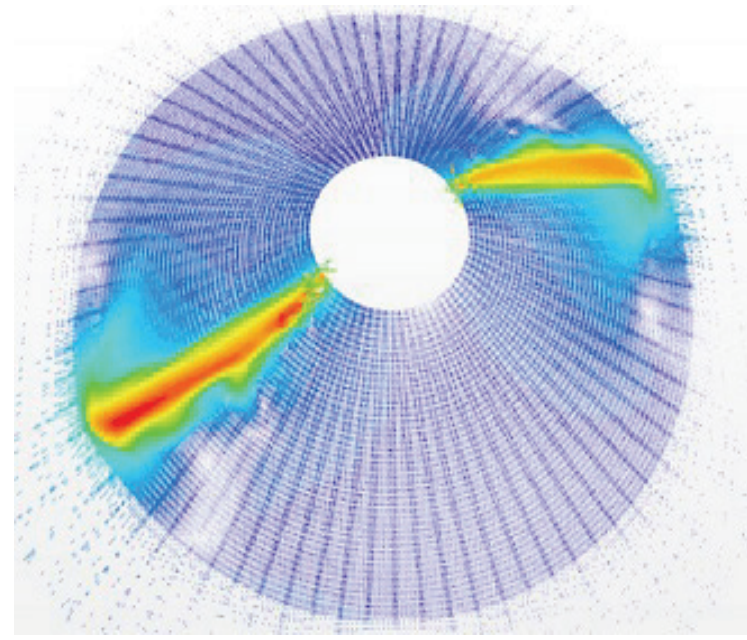

(d). UA $130^{\circ}$ Rotation in stable region

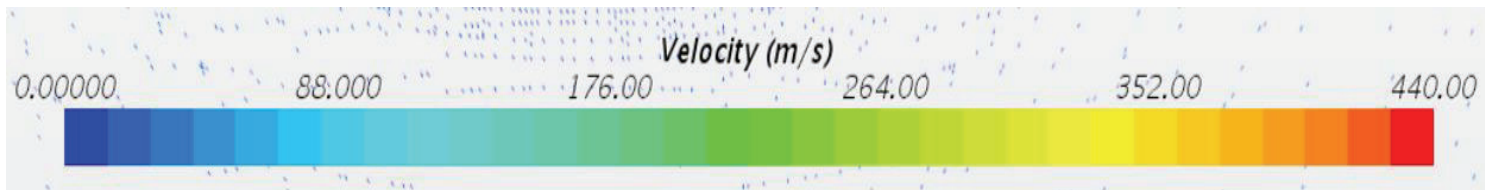

Figure 8. Detailed view of Spray pattern for static and rotating nozzle of UA 70 and 130 degrees in the stable region.

From work of Magnus Sjoberg (2001), it was seen that performance metrics improved while using a rotating injector. Having compared the static case numerically, the same injector was now rotated at $1500 \mathrm{rpm}$ to visualize the spray pattern. Since the dispersion feature in the rotating frame of the injector has a complex structure, it was not 
possible to compare the volume of fraction of static and rotating cases. The effect of spray pattern for static and rotating injector of UA 70 degree and UA 130 degree at stable condition is presented in Figure 8. It can be observed that the velocity vector is stronger in the UA 130-degree case and more so in the rotating frame. Thus, the effect dispersion is clearly improved under the rotating frame.

\section{Effect of Combustion}

\subsubsection{Effect of in-cylinder combustion}

From Figure 9, it can be seen that the cylinder pressure for a rotating injector is lesser by 3.3 bar with a corresponding decrease of 2.95 Joules of heat release (HRR) per cycle. The calculated thermal efficiency for the static case was $29.07 \%$ compared to $28.92 \%$ for the rotating injector. Although loss in thermal efficiency is only 0.15 $\%$, the $\mathrm{NO}_{\mathrm{x}}$ emission decreases by a good $14 \%$. It is observed that although the peak HRR value has decreased for the rotating case, the heat release spread is wider helping in reducing the cylinder temperature and pressure, which is attributed to the decrease in NOx with a very marginal decrease in efficiency.

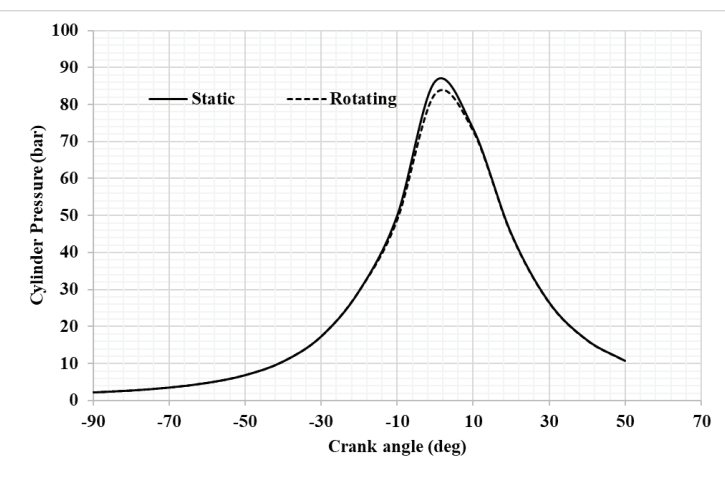

Cylinder Pressure

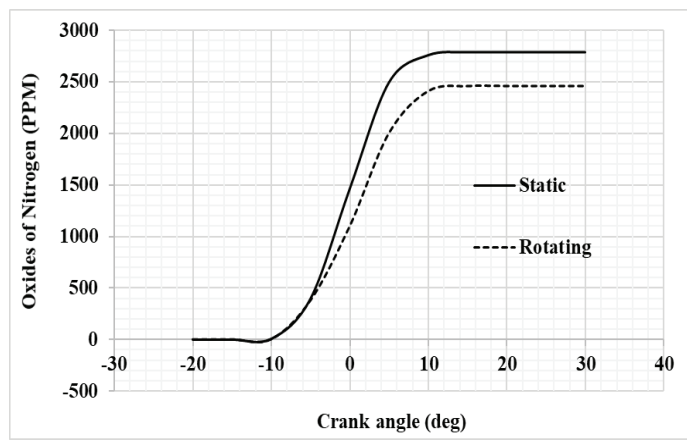

$\mathrm{NO}_{\mathrm{x}}$ emission

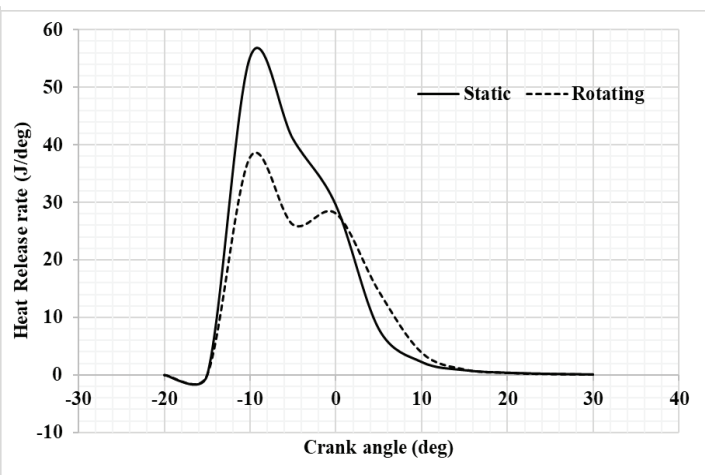

Heat Release Rate

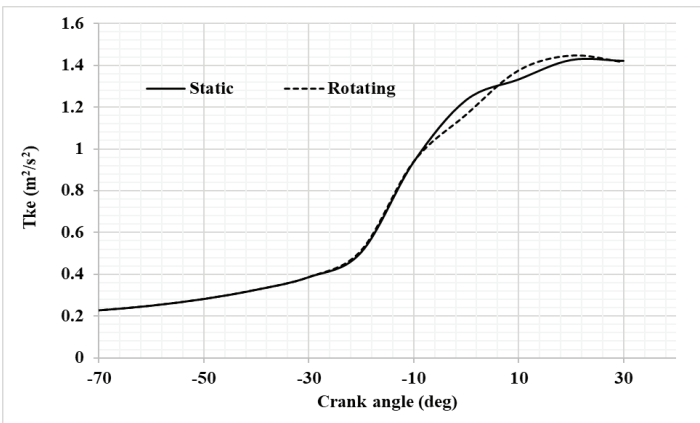

Turbulent kinetic energy

Figure 9. Combustion comparison between Static and Rotating injection for three holes at 23 deg bTDC injection. 


\subsubsection{Dispersion Vs Crank Angle}

The injection of fuel and dispersion needs to be studied at various crank angles. Figure 10 presents the cross sectional view for both the cases along with the HRR trace at locations where there is significant change between static and rotating cases. A cross sectional plane is $2 \mathrm{~mm}$ below the injector location for both static and rotating cases. The fuel droplets are visualized at selected crank angles corresponding to the HRR trace and analyzed. At CA 20 degrees bTDC, the fuel ejected from the rotating injector is slightly distorted compared to a near circular pattern in the static case. At CA 15 degrees bTDC, the spread near the wall is slightly higher for the static case. The peak HRR in both cases is at 10 degrees bTDC. The curvature of the dispersed fuel can be distinctly seen in the rotating case. Visually, the quantity of fuel injected from 23 to 10 degrees bTDC in the rotating injector appears to be lower than static injector. At 5-degree bTDC, there is a slight dip in the static HRR but more distinct valley in the rotating case. But the fuel injected at that time instant is more in the rotating case. Consequently, the HRR peaks up and reaches the same value at TDC. At the end of injection duration one can still observe residual unburnt fuel in the rotating case. This fuel further combusts to provide additional energy that can be clearly seen in the HRR trace.

From the HRR trace between TDC and 15 degrees aTDC (Figure 9 HRR plot), one can observe this increase in thermal output. Thus, the reason rotating injector in providing almost same thermal efficiency but with a lower $\mathrm{NO}_{\mathrm{x}}$ can be understood.

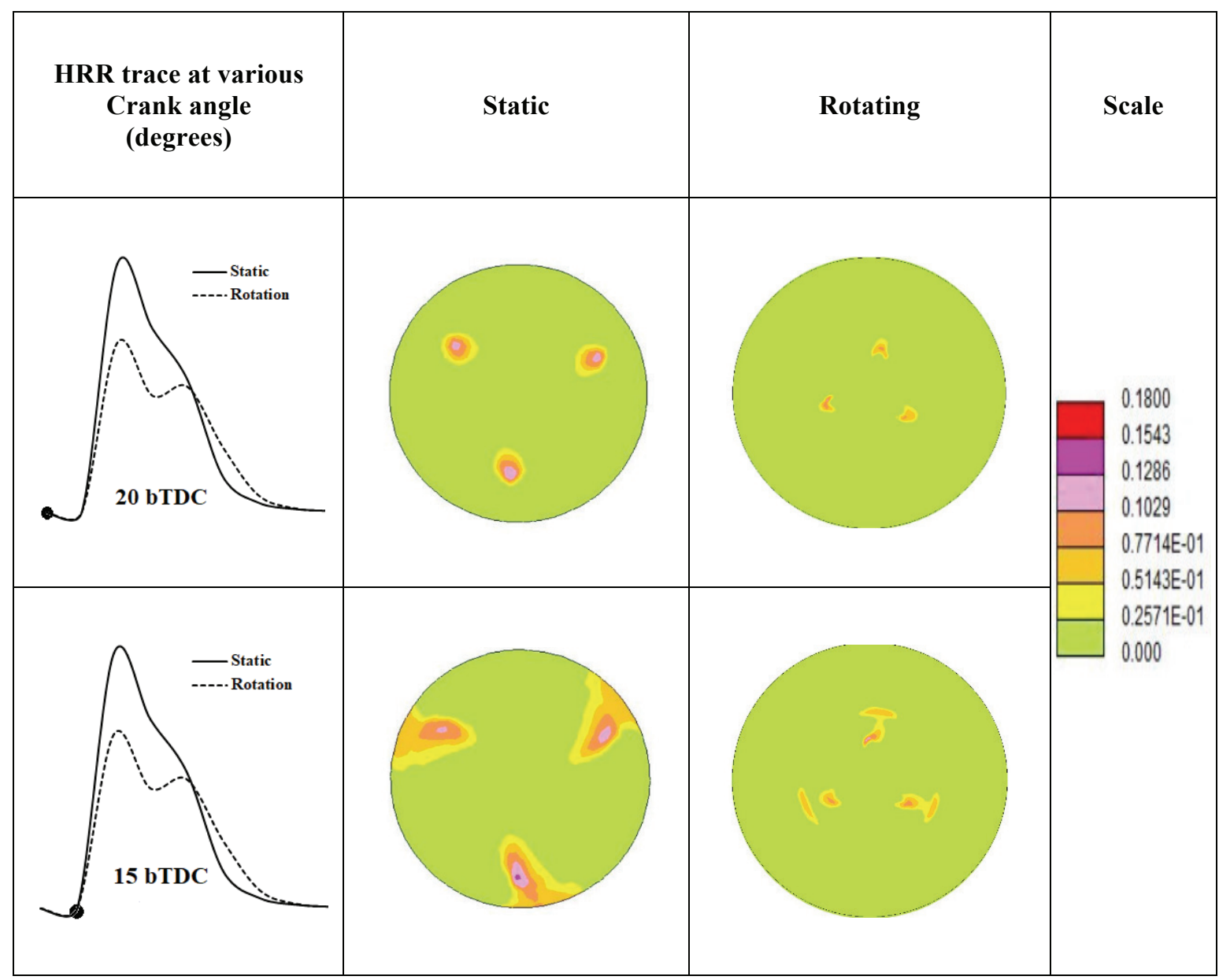




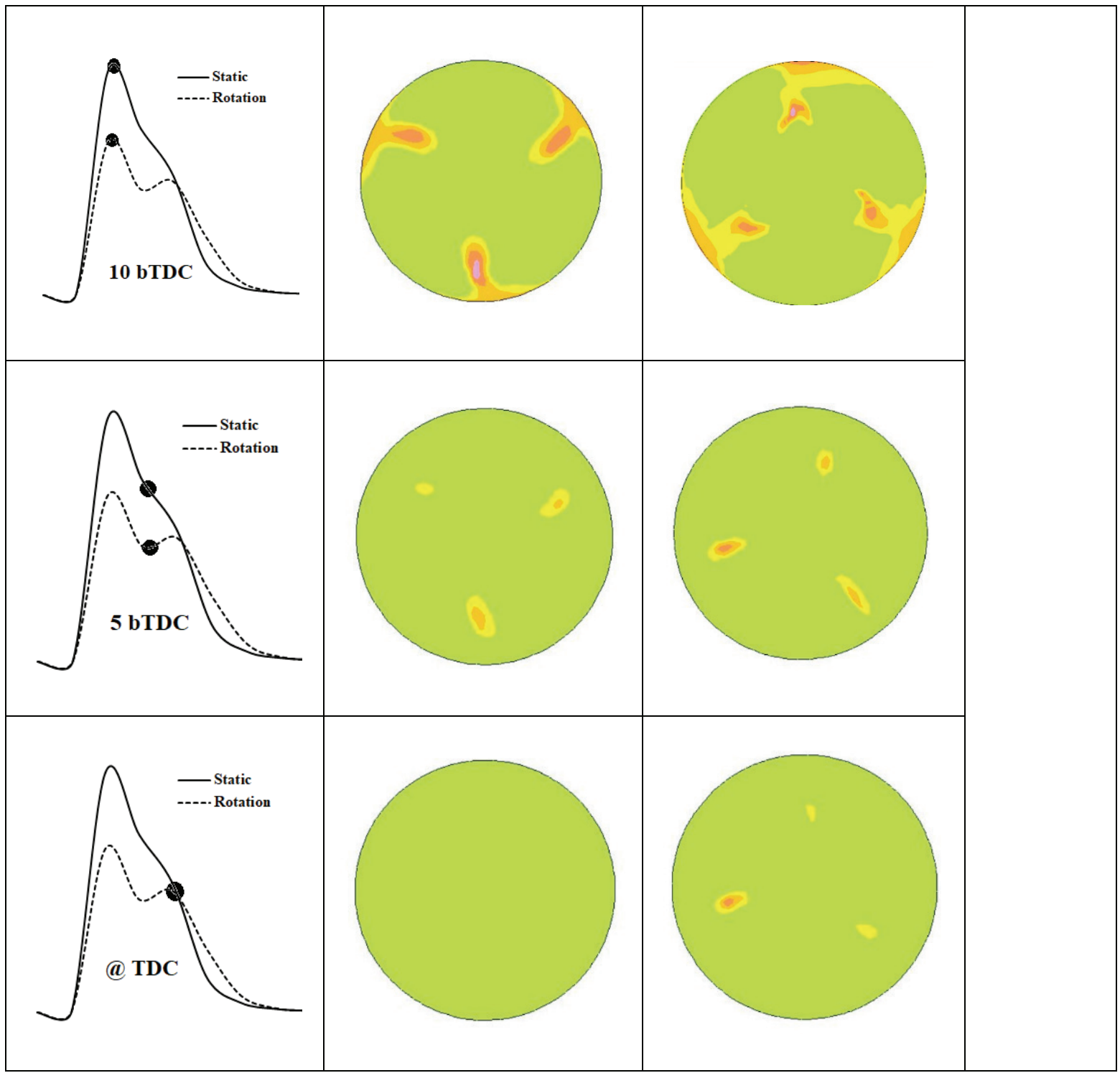

Figure 10. Comparison of fuel dispersion in static and rotating injector at different crank angles.

\subsubsection{Turbulent Kinetic Energy}

In so far as turbulent kinetic energy is considered, it was seen that both cases have a similar pattern and value. It is seen from Figure 9 that the turbulent kinetic energy plot for both static and rotation remains the same but deviates from 10 bTDC to 20 aTDC degrees. One can observe that the maximum difference occurs at TDC and 15-degree aTDC crank angle.

The turbulent kinetic energy contours at the cross-section $2 \mathrm{~mm}$ below the injector are now extracted for TDC and 15 degrees aTDC and presented in Figure 11. The injection at TDC is now considered. In The static case, one can observe the higher Tke in line with the injection direction, whereas, in the rotating injector, the rotational direction 
is seen to influence the Tke direction with three strong 'eyes'. Also, the Tke closer to cylinder wall is stronger in the static case, but the effect of rotation helps in creating a swirl inside the cylinder without much influence near wall. In so far as the 15-degree aTDC case is considered, one can see that the strong 'eye' of Tke is at six locations. The static case at 15-degree aTDC is seen to be similar to that of injection at TDC but a little stronger near wall. The effect of rotating injector can be very clearly seen. This effect also happens with a delay. This was also seen in fuel in dispersion plot in Figure 10 at TDC for rotating injector. This also explains why the HRR value between at TDC to 15 degrees aTDC is higher for the rotational injector (HRR trace, Figure 9). However, as this simulation is only for one cycle with a nozzle sweep of 121.5 degrees, it expected that the Tke will be much higher when the engine is run continuously as was seen in the cold flow simulation.

\section{Crank angle \\ (degrees)}

(a) TDC

15 aTDC

Scale
$\left(\mathbf{m}^{2} / \mathbf{s}^{2}\right)$

\section{Static}
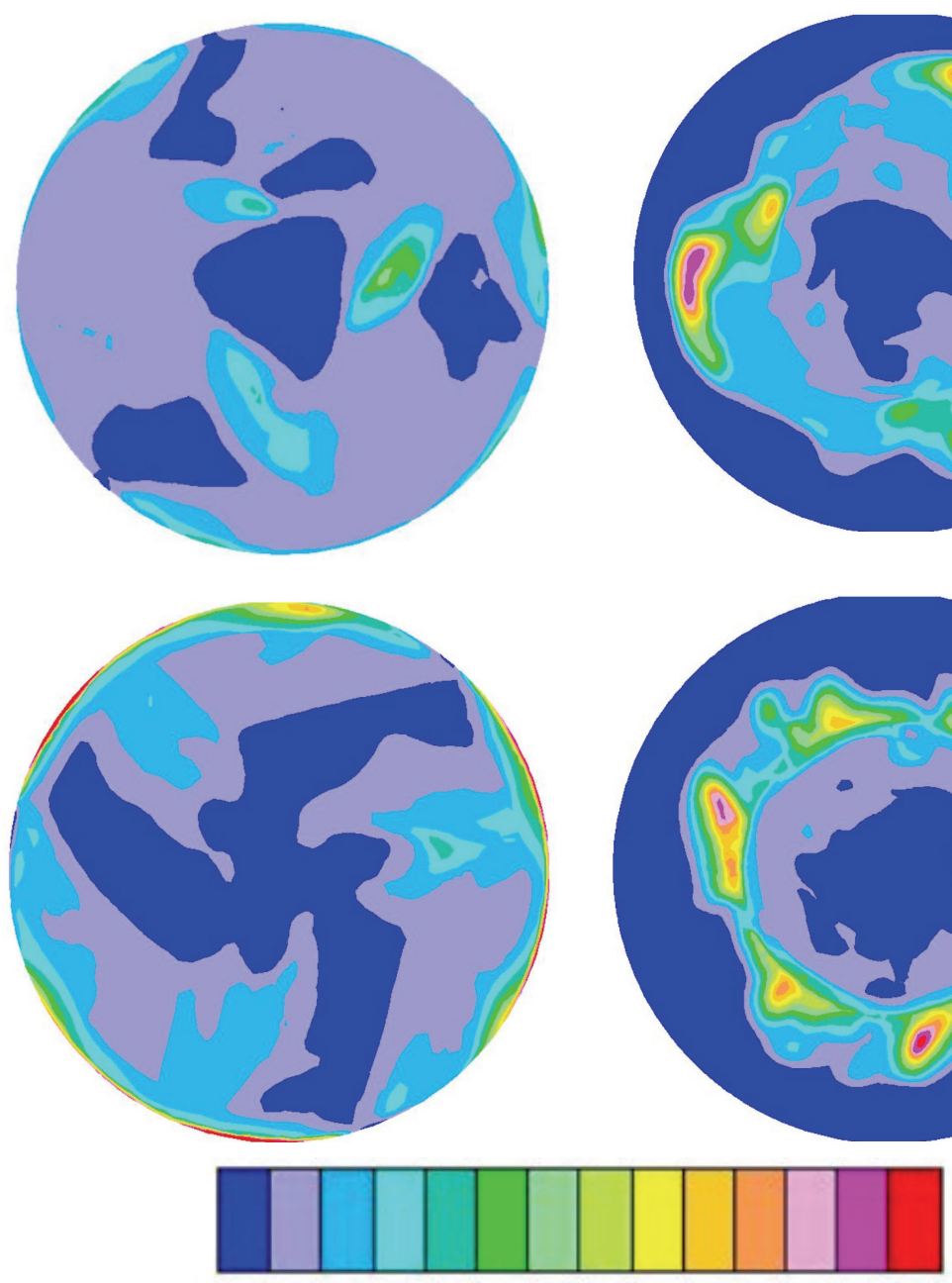

Rotating
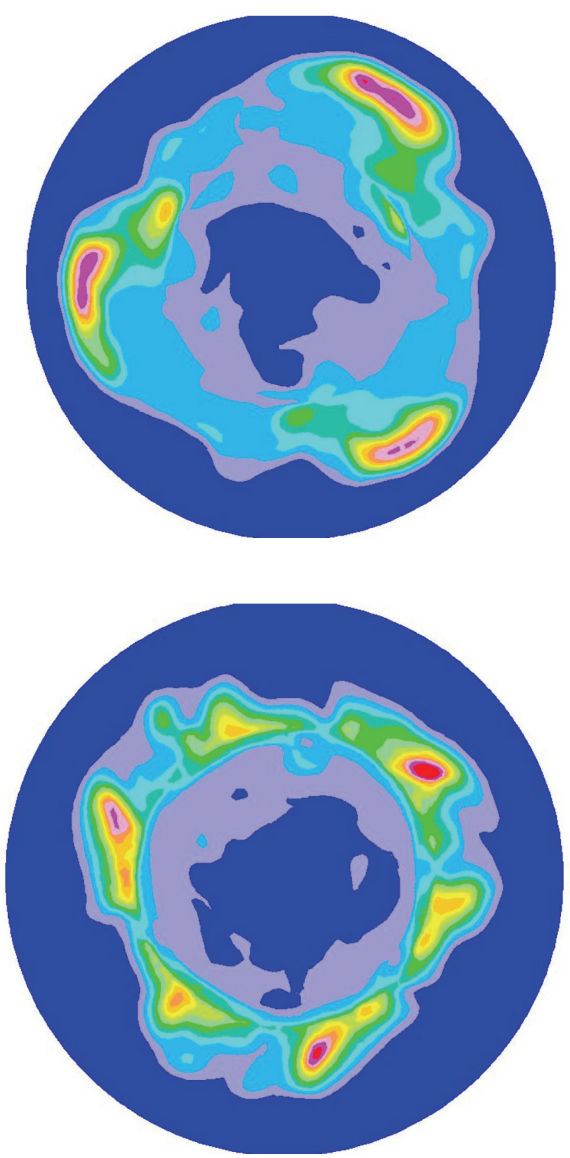

Figure 11. Cross sectional view of Turbulent kinetic energy for static and rotating. 


\section{CONCLUSIONS}

A numerical investigation has been done for two different nozzle configurations, namely, UA 70 degree and UA 130 degree, under both static and rotating conditions, and also combustion study was done for $839 \mathrm{CC}$ engine with three-hole static injector being compared with rotating injector.

1. The spray width peaks for both cases during the initial and final phases of needle lift, however, remain stable during the remaining period. The SW for UA130 degree is higher than that of UA 70 degree for both static and rotating conditions.

2. From the volume fraction analysis, UA 130 -degree SW has more fuel content than UA 70 degree. This was also confirmed by performing a student $t$-test.

3. The change in UA has a change in sac space. The higher sac space does enhance rotation of fluid as it exits, and a possible cause for increased SW.

4. The combustion analysis shows that the rotating injector performs better by lowering the $\mathrm{NO}_{\mathrm{x}}$, with only a marginal decrease in efficiency with a lower peak but wider heat release spread that helps in reducing the cylinder temperature and pressure.

5. The effect of fuel dispersion on HRR was also seen and the plausible reason for a larger HRR spread with a smaller peak for rotating nozzle explained. The effect of rotating nozzle on Tke was also captured. But as the simulation was only for one cycle, the change was only visualized between TDC and 15degree aTDC. However, it is expected to be much higher once the injector is under continuous motion due to its inertia.

6. This rotating injector must be considered as an "imperfect dynamic system." Thus, there is a need to investigate the performance considering the modelling presented in Bucolo et al. (2019) in order to estimate the benefits that might arise in the real case.

7. Further reduction in emission characteristics may be obtained by using dual fuel (natural gas/diesel) as observed by Yu et al. (2015).

\section{REFERENCES}

Bergstrand P, Denbrantt I. 2001. Diesel combustion with reduced nozzle hole diameter. SAE technical paper: 2001-01-2010.

Bergstrand P, Forsth M, Denbrantt I. 2002. The influence of hole diameter on flame lift-off length. ILASSEurope 2002, Zaragoza, Spain.

Blessing M, Konig G, Kruger C, Michels U, Schwarz V. 2003. Analysis of flow and cavitation phenomena in diesel injection nozzles and its effects on spray and mixture formation. SAE technical Paper No. 2003-011358.

Bucolo M, Buscarino A, Famoso C, Fortuna, Frasca M. 2019. Control of imperfect dynamical systems. Nonlinear Dynamics; 98 (4):2989-2999.

C Soteriou, Andrews RJ, Torres N, Smith M, Kunkulagunta R. 2001. Through the diesel nozzle hole - a journey of discovery. In: Proc ILASS Americas 14th annual conference on liquid atomization and spray systems. Dearborn, Michigan, USA.

Dec JE. 1997. A conceptual model of DI diesel combustion based on laser-sheet imaging. SAE technical paper 970873.

Han JS, Lu PH, Xie XB, Lai MC, Henein NA. 2002. Investigation of diesel spray primary breakup and development for different nozzle geometries. SAE technical Paper No. 2002-01-2775. 
Habchi C, Dumont N, Simonin O. 2008. Multidimensional simulation of cavitating flows in diesel injectors by a homogeneous mixture modeling approach. Atomization Sprays; 18 (2):129-62.

Hajime Fujimoto, Tsukasa Hori, Jiro Senda. 2009. Effect of Breakup Model on Diesel Spray Structure Simulated by Large Eddy Simulation, 2009-24-0024.

Iida N, Wakimoto K, Takahashi S, Nikolic D. 2001. Effect of nozzle diameter and Egr ratio on the flame temperature and soot formation for various fuels. SAE technical paper 2001:2001-01-1939.

J. Benajes, J. V. Pastor, R. Payri, A. H. Plazas. 2004. Analysis of the Influence of Diesel Nozzle Geometry in the Injection Rate Characteristic, Journal of Fluids Engineering, Vol. 126/63, January 2004.

Kobori S, Kamimoto T, Kosaka H. 1996. Ignition, combustion and emissions in a DI diesel engine equipped with a micro-hole nozzle. SAE technical paper 1996:960321.

Lee JW, Min KD, Kang KY, Bae CS, Giannadakis E, Gavaises M. 2006. Effect of piezo-driven and solenoiddriven needle opening of common-rail diesel injectors on internal nozzle flow and spray development. International Journal of Engine Research; 7(6):489-502.

Montgomery DT, Chan M, Chang CT, Farrell PV, Reitz RD. 1996. Effect of injector nozzle hole size and number on spray characteristics and the performance of a heavy-duty D.I. diesel engine. SAE technical paper 1996:962002.

Magnus Sjoberg. 2001. The rotating injector as a tool for exploring DI diesel combustion and emission formation processes, Doctoral Thesis, ISSN 1400-1179.

Naber JD, Siebers DL. 1996. Effects of gas density and vaporization on penetration and dispersion of diesel sprays. SAE technical paper 1996: 960034.

Nishida K, Zhang W, Manabe T. 2008. Effects of micro-hole and ultra-high injection pressure on mixture properties of D.I. diesel spray. SAE Trans 2008; 116:421-9.

Payri F, Bermudez V, Payri R, Salvador FJ. 2004. The influence of cavitation on the internal flow and the spray characteristics in diesel injection nozzles. Fuel; 83: 419-31.

Payri R, Garcia JM, Salvador FJ, Gimeno J. 2005. Using spray momentum flux measurements to understand the influence of diesel nozzle geometry on spray characteristics. Fuel 2005; 84:551-61.

S. Hossainpour, A.R. Binesh. 2009. Investigation of fuel spray atomization in a DI heavy-duty diesel engine and comparison of various spray breakup models, Fuel, 88, pp. 799-805.

Su TF, Chang CT, Reitz RD, Farrell PV, Pierpont AD, Tow TC. 1995. Effects of injection pressure and nozzle geometry on spray Smd and D.I. diesel emissions. SAE technical paper 1995:952360.

Siebers D, Higgins B. 2001. Flame Lift-off on direct-injection diesel sprays under quiescent conditions. $S A E$ technical paper 2001:2001-01-0530.

STAR-CCM+. 2017. Version 12.02.011, https:// download. Industry software. automation. siemens. com, 2017.

STAR-CD. 2016. Version 4.26.011, https:// download. Industry software. automation. siemens. com.

Stiesch G. 2003. Modelling engine spray and combustion processes, Springer Ed.

X. Margot, R. Payri, A. Gil, M. Chavez, A. Pinzello. 2008. Combined CFD-Phenomenological Approach to the Analysis of Diesel Sprays under Non-Evaporative Conditions, SAE Technical Paper Series, 2008-01-0962.

Xusheng Zhang, Seoksu Moon, JianGao, Eric M. Dufresne, Kamel Fezzaa, Jin Wang. 2016. Experimental study on the effect of nozzle hole-to-hole angle on the near-field spray of diesel injector using fast X-ray phase-contrast imaging, Fuel; 185, 142-150. 
Yu Hongliang, Duan Shulin, Sun Peiting. 2015. Comparative analysis between natural gas/diesel (dual fuel) and pure diesel on the marine diesel engine, Journal of Engineering Research; 3(4), 1-15.

Yu Hongliang, Duan Shulin, Sun Peiting. 2017. Numerical simulation of combustion progress on dual fuel engines with different turbulence models, Journal of Engineering Research; 5(4), 225-235. 